\title{
A STUDY ON PREVALENCE OF ROAD TRAFFIC ACCIDENTS AND ITS RISK FACTORS IN JHANSI AND AROUND JHANSI CITY (U. P.)
}

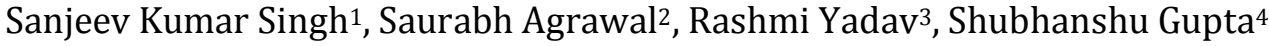

\section{HOW TO CITE THIS ARTICLE:}

Sanjeev Kumar Singh, Saurabh Agrawal, Rashmi Yadav, Shubhanshu Gupta. "A Study on Prevalence of Road Traffic Accidents and its Risk Factors in Jhansi and around Jhansi City (U. P.)". Journal of Evolution of Medical and Dental Sciences 2015; Vol. 4, Issue 43, May 28; Page: 7499-7508, DOI: 10.14260/jemds/2015/1088

ABSTRACT: BACKGROUND: Expansion in network, motorization and urbanization in the country has been accompanied by a rise in road accidents leading to road traffic injuries (RTIs). Accident represents a major epidemic of non-communicable disease in present century. OBJECTIVE: To study the prevalence of Road Traffic Accidents (RTAs) and its risk factors in Jhansi \& around Jhansi city. MATERIAL AND METHODS: A hospital based cross sectional study was carried out in MLB Medical College and Hospital, Jhansi and the cases sustaining road traffic injuries registering from 1 January 2013 to 31 July 2014 were taken irrespective of the place of accident. The data was entered in excel sheet and results were expressed as proportions and percentages. RESULTS: Among them maximum number of cases were in 21-30 years age group (30.53\%) followed by 31-40 years $(21.66 \%)$ and $>60$ years $(4.65 \%)$ shows the least no. of victims. In the study majority of cases were reported from Orchha Road (11.5\%). In the study it was observed that majority of accidents occur in winter season (37.24\%) and in night time (34.47\%).Among them 19.68\% victims stated that defective road as the most common condition associated with RTA followed by poor lighting (18.54\%). CONCLUSIONS: In this study majority of victims were younger, males, less educated and labourer by occupation. Among risk factors defective roads, poor lighting, excessive speed, overloading and alcohol consumption were found causing RTAs.

KEYWORDS: Road traffic accidents, Risk factors, Victims.

INTRODUCTION: Accident represents a major epidemic of non-communicable disease in present century. World health organization defined accidents as "an unpremeditated event resulting in recognizable damage". An accident or a mishap is an incidental and unplanned event or circumstance, often with lack of intention or necessity. It usually implies a generally negative outcome which might have been avoided or prevented had circumstances leading up to the accident been recognized, and acted upon, prior to its occurrence.

A Road Traffic Accident(RTA) can be defined as, 'An event that occurs on a way or street open to public traffic; resulting in one or more persons being injured or killed, where at least one moving vehicle is involved. Thus RTA is a:

1. Collision between vehicles.

2. Between vehicles and pedestrians.

3. Between vehicles and animals.

4. Between vehicles and geographical or architectural obstacles.

There were 1.24 million deaths on the world's roads in 2010, similar to the number of deaths in 2007. This shows number of road traffic deaths each year has not increased but remains unacceptably high.Nearly two-thirds (62\%) of the traffic accidents worldwide have been found to be taking place in 10 countries, which form slightly more than half (56\%) of the world's population, with 
the maximum being in India followed by China, United States, The Russian Federation, Brazil, Iran, Mexico, Indonesia, South Africa and Egypt.[1] Evidence indicates that although India has one percent of the world's vehicles, it accounts for as high as six percent of world's RTAs. ${ }^{[2]}$

A number of factors contribute to the risk of collision, including vehicle design, speed of operation, road design, faulty vehicle, road environment, driver skill and/or impairment, and driver behavior. Worldwide, motor vehicle collisions lead to death and disability as well as financial costs to both society and the individuals involved. To the best of my knowledge, there was no study done in respect of Road Traffic Accidents in Jhansi \& around Jhansi city. This study was expected to fill this gap and focuses on prevalence of Road Traffic Accidents and its risk factors. With these perspectives, we conducted the present study. Our objective was to study the prevalence of Road Traffic Accidents (RTA), its risk factors and accident prone sites (black spots), which form the crucial determinants of the RTA in Jhansi \& around Jhansi city.

MATERIAL AND METHODS: A hospital based cross sectional study was carried out in MLB Medical College and Hospital, Jhansi and the cases sustaining road traffic injuries registering from 1st January 2013 to $31^{\text {st }}$ July 2014 were taken irrespective of the place of accident. Total patients registered in MLB Medical College, Jhansi were approximately 4,50,000 in this time period. Out of which number of total road traffic injuries were 8435, among them 6545 RTA patients discharged on slip basis and 1890 RTA patients were admitted in various departments of MLB Medical College Hospital, Jhansi.

2535 RTA patients were taken as study population. We had interviewed personally 2190 RTA patients. Out of which 645 patients were slip discharged and 1545 were admitted. For the purpose of the study, case definition of RTA was, an event that occurs on a way or street open to public traffic; resulting in one or more persons being injured or killed, where at least one moving vehicle is involved. Spot deaths (Death at the accidental spot), deaths during transportation, attending private hospitals, discharged from PHC, treated by quak, neglected injuries and discharged on slip but couldn't interviewed (Missed patients) were not included in the study.

A pretested, semi-structured questionnaire was used to study socio-demographic variables, place of injury and various risk factors related to RTAs. When patient was in a fully conscious state, questions asked by patients, otherwise history was obtained preferably from persons who were either present at the time of accident or who brought the patient to medical college. The victims/relatives of the RTA cases, who attained either the casualty, orthopedic outpatient clinic, surgical and E.N.T. outpatient clinic or admitted in the wards were interviewed to obtain the information about the circumstances leading to the accident. The medico legal records, 108 ambulance record, admitted patients records from record section, OPD and emergency slip register records (In which road traffic accident patients was separately mentioned), and case-sheets of the victims were referred for collecting additional information and where necessary for cross-checking.

The data was entered in excel sheet and results were expressed as proportions and percentages.

RESULTS: Figure 1 shows that maximum number of cases were in 21-30 years age group (30.53\%) followed by 31-40 years(21.66\%) and $>60$ years(4.65\%) shows the least no. of victims. Out of 2535 RTA victims 1885 were males constituting major bulk of RTA victims, while 650 were females (Figure 2). In the study most of the patients were laborer by occupation i.e. skilled and unskilled which constitute $25.43 \%$ and $25.48 \%$ respectively. It was followed by students constituting $16.07 \%$ 


\section{ORIGINAL ARTICLE}

(Figure 3). In Figure 4 it was observed that out of 2190 victims, majority were educated up to primary school $(29.77 \%)$. It was followed by illiterate patients $(27.2 \%)$ and educated up to secondary school $(22.37 \%)$.

In the study majority of cases were reported from Orchha Road (11.5\%). It was followed by Garutha Road (5.85\%) and Parichha (5.84\%). Cases reported from Pannhari, Burha, Lalitpur, Karera and Shivpuri were less in number (Figure 5). Distribution of study respondents in terms of different variables is given in Table 1. Among victims (1890) of road traffic accident majority were admitted in Surgery ward (45\%) followed by emergency ward (36\%). In the study most persons were slip discharged (77.59\%) and coming to MLB Medical College from Jhansi (50\%). In this study we compared the most common causes of deaths in Jhansi with World and India. Ischemic Heart Diseases was ranked 1 in both World and India but in Jhansi its ranked $6^{\text {th }}$. In Jhansi most common cause of death was found Perinatal Conditions during study (Table 2).

Subject studied for risk factors causing road traffic accidents is given in Table 3. In the study it was observed that majority of accidents occur in winter season (37.24\%) and in night time (34.47\%). Out of 2535 patients 2190 were interviewed, among them $19.68 \%$ victims stated that defective road as the most common condition associated with RTA followed by poor lighting(18.54\%). Among interviewed patients $33.97 \%$ were travelling on motor cycle at the time of accidents. Second most prone vehicle for accident was observed to be 3 wheeler (Ape, Rickshaw) constituting $26.67 \%$. In the study majority (41.50\%) were injured due to excessive speed at the time of driving and it was followed by overloading of vehicle (40.46\%). 13.26\%of respondents reported that they had alcohol while/before driving.

DISCUSSION: In present study it was found that maximum number of cases of Road Traffic accidents were in the age group of 21-30 years of age (30.53\%), males (74.34\%), educated up to primary school (29.77\%) and laborer by occupation (51\%). Similar observation was reported by Thompson L and Steiner $\mathrm{D}$ et al where drivers at fault are generally younger.[3] Huda $\mathrm{N}$ et al from Moradabad revealed that the majority of victims were in the age group of $11-44$ years $(81.89 \%)$ and males (71\%).[4] Singh D et al from Chandigarh found that male preponderance (89.6\%) was seen in the study.[5] Similar results were seen in a study conducted by Ghaffar A, Hyder A, Masud TI et al from Pakistan that road traffic injuries were higher in males, those 16-45 years old and in labourers.[6] Jha $\mathrm{N}$ et al from South India ${ }^{[7]}$ and Abhishek Singh et al from Haryana ${ }^{[8]}$ revealed that $21.4 \%, 31.02 \%$ were educated up toprimary school respectively.

When enquired about risk factors causing Road Traffic accidents it was seen that majority of accidents occur in winter season (37.24\%) and in night time (34.47\%). Similar results were found in the study conducted by Chalya PL et al Tanzania where $34.8 \%$ accidents occurred at night. ${ }^{[9]}$ logical to think that during night time, drivers are drowsy their awareness level is less. Driver fatigue('falling asleep at the wheel') is a major cause of road accidents, accounting for up to $20 \%$ of serious accidents on motorways and monotonous roads in Great Britain. ${ }^{[10]}$ But Kiran ER et al in 2004 reported that the maximum number (48.5\%) of RTAs occurred in rainy season, followed by 54(33.5\%) in winter.[11]

In this study defective road (19.68\%) and poor lighting (18.54\%) were found as a cause of accident among most of cases. Condition of vehicle is also an important risk factor for Road Traffic Accidents. Among victims majority (41.50\%) were injured due to excessive speed at the time of driving and it was followed by overloading of vehicle (40.46\%). In high-income countries, speed 
contributes to about $30 \%$ of deaths on the road, while in some low-income and middle-income countries, speed is estimated to be the main contributory factor in about half of all road crashes.[12]

In the study $13.27 \%$ of victims had consumed alcohol at the time of accident. Study by Agarwal et al..13]and Kiran ER et al.[11] showed that 26\%,13\% of subjects had the history of alcohol consumption during driving.

CONCLUSIONS: This study found that majority of victims was younger, males, less educated and labourer by occupation. Most of the RTAs were reported at night and in winter season. This is due to poor visibility at night and fog during winter. In the study most common vehicles associated with RTA were found motor Cycle and three wheelers which was most common mode of transport in Jhansi, includes Ape, Rickshaw, Vikram, etc. Orchha Road with 11.5\% casualties in period of 19 months was hotspot for accidents in Jhansi Region. Among risk factors defective roads, poor lighting, excessive speed, overloading and alcohol consumption were found causing RTAs. Perinatal conditions with 316 deaths was ranked first in Jhansi Region as cause of Death while RTAs ranking at 9th position with 97 deaths. RTA ranked at 1 position in all causes of Trauma/Accidents with respect to death.

RECOMMENDATIONS: In this study we observed that road injuries was ranked at No. 9 among cause of deaths in Jhansi region. You can fathom the importance of road safety measures from it. Road accidents are an outcome of the interplay of various factors, some of which are the length of road network, vehicle population, human population and adherence/enforcement of road safety regulations. Jhansi is urban region but still it's in phase of development, so roads in Jhansi regions are not well maintained, the dividers, speed breakers are irregularly spaced and are very unpredictable. Also road lighting in Jhansi region is also very poor, road visuality at night time is poor. The traffic in Jhansi region is not well guided, people do not care about traffic rules here. Such things should be monitored and controlled by government.

In India personalized vehicles are increasing with the same growth rate. Projection of the present trend of vehicles usage reveals a rather ugly and unsustainable situation both in terms of traffic congestion and safety. Most important method to bring down accidents is strict enforcement of speed limits. Driving tests for issue of driving license is to be made more stringent and foolproof. Lower age limit for two wheeler and Heavy Vehicle license should be raised to 21. Helmet should be made compulsory by law in all countries and existing traffic rules should be strictly enforced. Newspaper, Television and other media should be effectively used for Public Safety Awareness.

ACKNOWLEDGEMENT: The authors would like to thank all the participants and their relatives in the study for their cooperation.

\section{REFERENCES:}

1. WHO World Health Organization. http://www.who.int/roadsafety/news/2010/unrsc_decade_of_action/en/

2. Fitzgerald M, Dewan Y, O’Reilly G, Mathew J, McKenna C et al. India and the management of road crashes: Towards a national trauma system, Indian Journal of Surgery. 2006; 68(4):226232. 


\section{ORIGINAL ARTICLE}

3. Thompson L, Steiner D, Sosin DM, Bolen JC et al. The Task Force on Community Preventive Services, "Reviews of Evidence Regarding Interventions to Increase Use of Child Safety Seats," American Journal of Preventive Medicine. 2001; 21(4): 31-47.

4. Huda $\mathrm{N}$ et al. Pattern of Orthopaedics injuries among patients attending the emergency department in a tertiary care hospital: an analytical study, Actamedica international. 2014; 1(1): 13-21.

5. Singh D and Kumaran M et al. Profile of Road Traffic Fatalities in Adults-A 40 Year Study in Chandigarh Zone of North West India, J Indian Acad Forensic Med. 2014; 36(1).

6. Ghaffar A, Hyder A and Masud TI et al. The burden of road traffic injuries in developing countries: The 1st national injury survey of Pakistan, Public health. 2004; 118(3): 211-217.

7. Jha N, Srinivasa DK, Roy G, Jagdish S et al. Epidemiological study of road traffic accidents cases: A study from south India, Indian Journal of Community Medicine. 2004; 24(1):20-24.

8. Singh A and Bhardwaj A et al. An epidemiological study of road traffic accident cases at a tertiary care hospital in rural Haryana, Indian Journal of Community Medicine. 2011; 23(2).

9. Chalya PL and Mabula JB et al, Injury characteristics and outcome of road traffic crash victims at Bugando Medical Centre in North-western Tanzania, Journal of Trauma Management \& Outcomes. 2012; 6(1) doi: 10.1186/1752-2897-6-1.

10. Naing, Claire L, Hill J, Maguire M, Schick S, Eggers A, Pastor C, Elslande PV et al. Driving taskrelated factors. 2008.

11. Kiran ER et al. Prospective Study on Road Traffic Accidents, JPAFMAT. 2004; 4: ISSN 09725687.

12. World report on road traffic injury prevention, http://www.who.int/violence_injury_prevention.

13. Agarwal A et al. Sociodemographic profile of road traffic accident victims admitted by emergency surgical OPD by tertiary care hospital, Journal of Postgraduate Medicine, study and research. 2012; 1: 15-18.

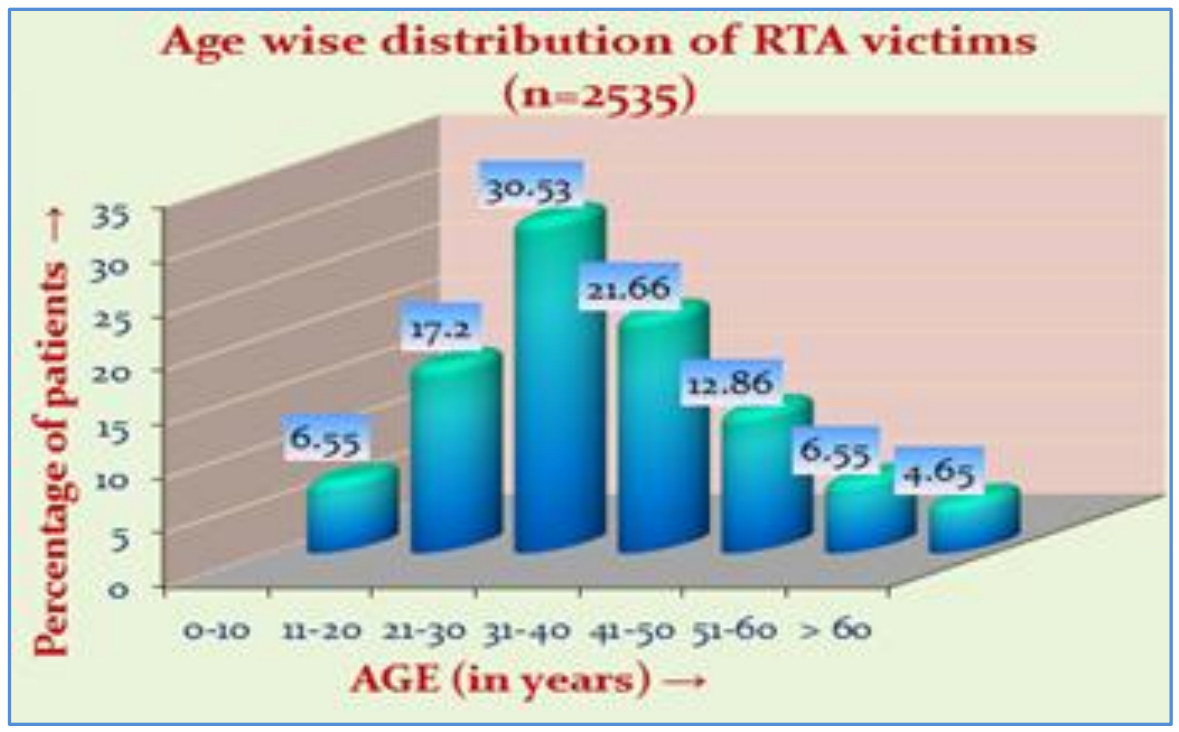

Figure 1: Distribution of cases according to age 


\section{ORIGINAL ARTICLE}

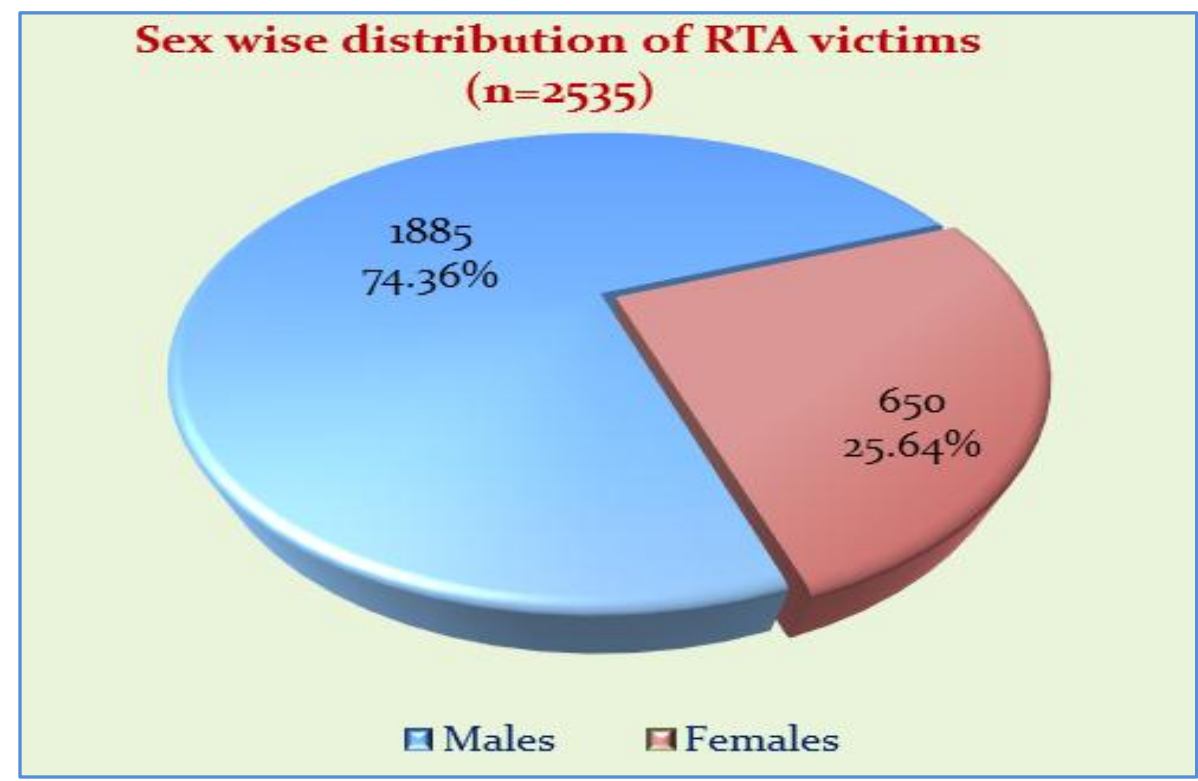

Figure 2: Distribution of cases according to gender

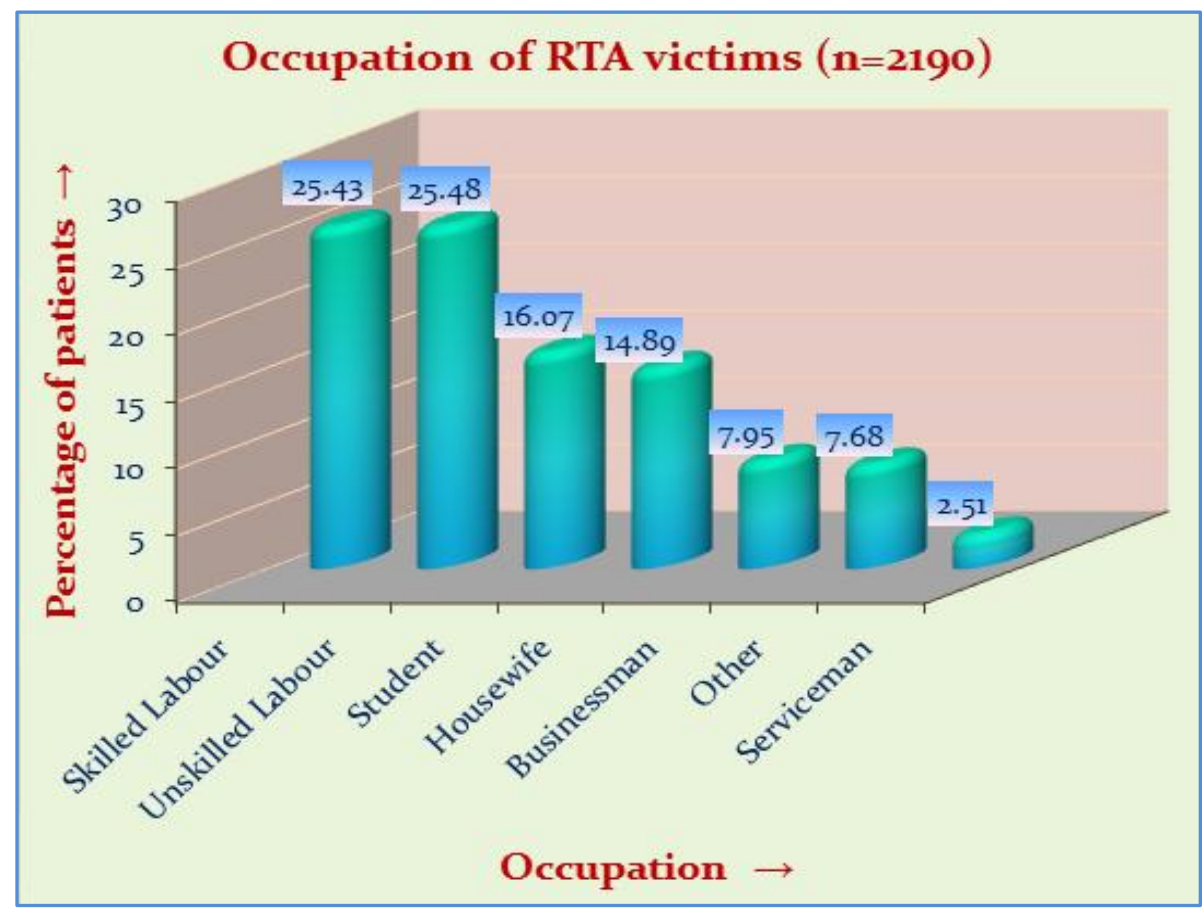

Figure 3: Distribution of cases according to occupation 


\section{ORIGINAL ARTICLE}

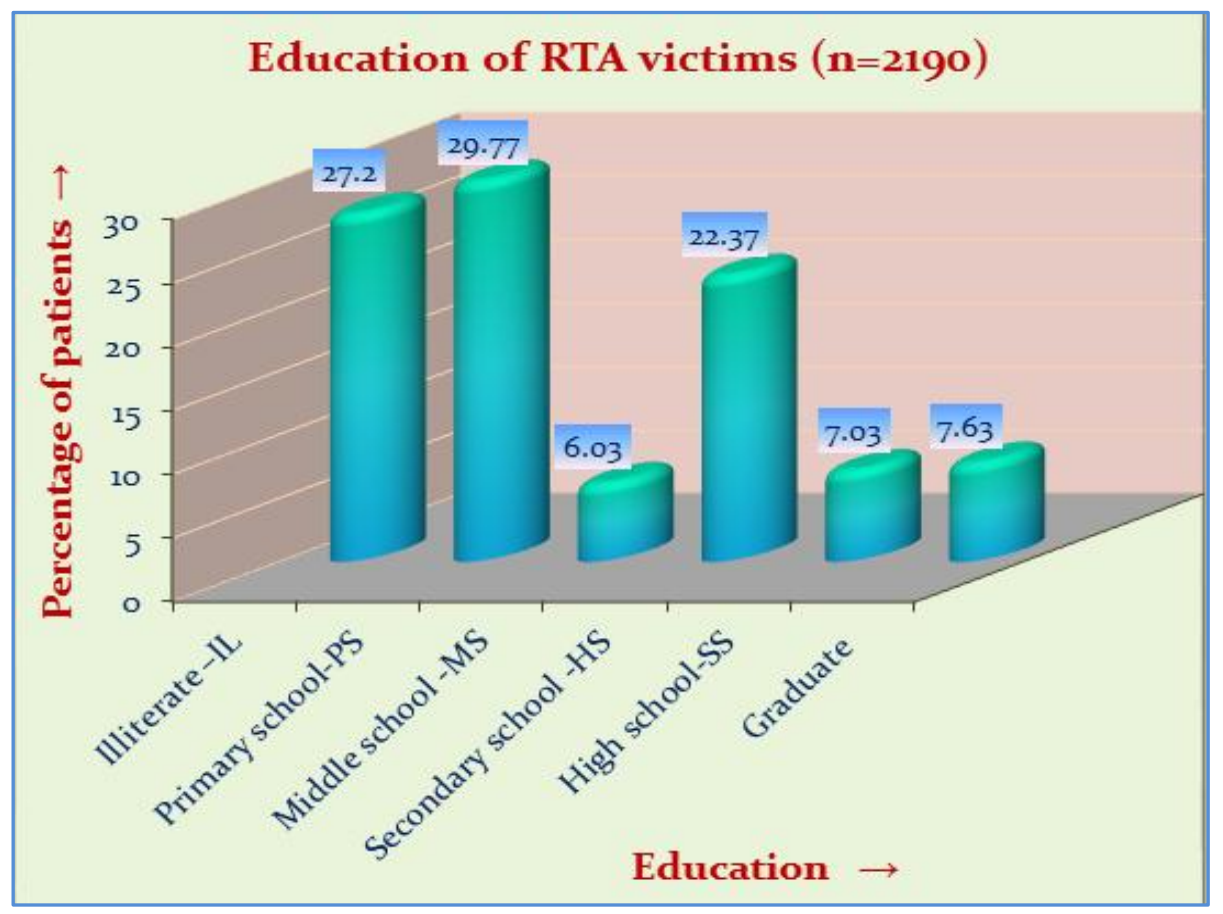

Figure 4: Distribution of cases according to education

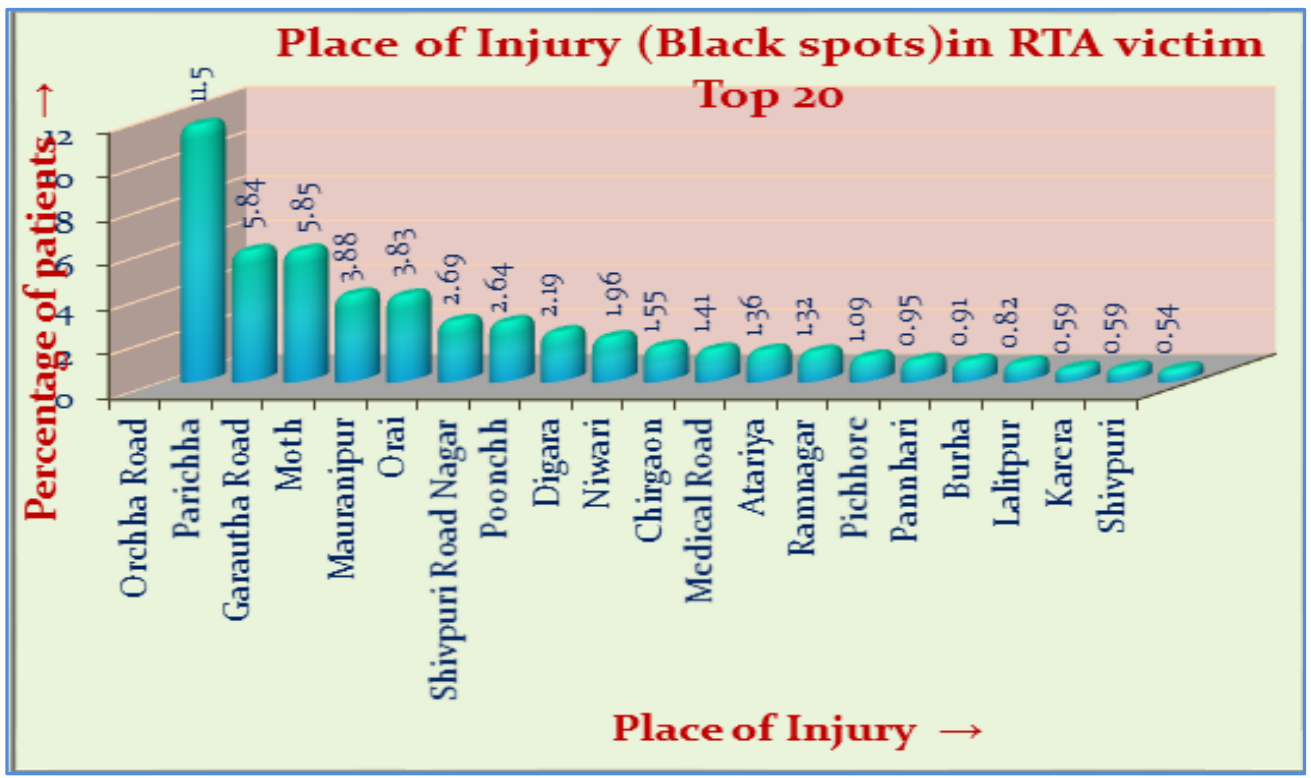

Figure 5: Distribution of cases according to place of injury 
ORIGINAL ARTICLE

\begin{tabular}{|c|c|c|c|}
\hline \multicolumn{2}{|l|}{ Variables } & No. of cases & Percentage \\
\hline \multirow[t]{3}{*}{ Wards } & Emergency & 679 & 35.92 \\
\hline & Others & 1211 & 64.08 \\
\hline & Total & 1890 & 100 \\
\hline \multirow[t]{7}{*}{ Fate of RTA victims } & Absconded & 641 & 7.60 \\
\hline & Discharged & 1135 & 13.45 \\
\hline & Expired & 81 & 0.96 \\
\hline & LAMA & 20 & 0.23 \\
\hline & Referred & 13 & 0.15 \\
\hline & Slip discharged & 6545 & 77.59 \\
\hline & TOTAL & 8435 & 100.00 \\
\hline \multirow[t]{11}{*}{ District } & Jhansi & 1270 & 50.09 \\
\hline & Tikamgarh & 300 & 11.83 \\
\hline & Jalaun & 217 & 8.56 \\
\hline & Lalitpur & 185 & 7.29 \\
\hline & Mahoba & 136 & 5.36 \\
\hline & Datia & 94 & 3.7 \\
\hline & Hamirpur & 81 & 3.19 \\
\hline & Shivpuri & 80 & 3.15 \\
\hline & Chhatarpur & 63 & 2.48 \\
\hline & Kanpur & 19 & 0.74 \\
\hline & Total & 2445 & 100.00 \\
\hline
\end{tabular}

\begin{tabular}{|c|c|c|c|}
\hline Rank & $\begin{array}{l}\text { Top } 10 \text { causes of } \\
\text { Death in World }\end{array}$ & $\begin{array}{l}\text { Top } 10 \text { causes of } \\
\text { Death in India }\end{array}$ & $\begin{array}{l}\text { Top } 10 \text { causes of } \\
\text { Death in Jhansi }\end{array}$ \\
\hline 1 & Ischemic Heart Diseases & Ischemic heart disease & Perinatal Conditions(316) \\
\hline 2 & Stroke & Lower respiratory infections & Burns(313) \\
\hline 3 & COPD & Cerebrovascular disease & Septicemia(196) \\
\hline 4 & $\begin{array}{l}\text { Lower Respiratory } \\
\text { Infections }\end{array}$ & Perinatal conditions & Poisoning(181) \\
\hline 5 & Lung Cancer & $\begin{array}{l}\text { Chronic obstructive } \\
\text { pulmonary disease }\end{array}$ & Stroke(174) \\
\hline 6 & HIV/AIDS & Diarrheal disease & Ischemic Heart Diseases(160) \\
\hline 7 & Diarrheal Diseases & Tuberculosis & Tuberculosis(156) \\
\hline 8 & Diabetes Mellitus & HIV/AIDS & Malaria(108) \\
\hline 9 & Road Injuries & Road Injuries & Road Injuries(97) \\
\hline 10 & Hypertension & Self-inflicted injuries & Pneumonia(58) \\
\hline
\end{tabular}




\begin{tabular}{|c|c|c|c|}
\hline \multicolumn{2}{|l|}{ Risk Factors } & No. of cases & Percentage \\
\hline \multirow[t]{3}{*}{ Seasons } & Summer(April-July) & 513 & 31.84 \\
\hline & Rainy + Autumn(Aug-Nov) & 498 & 30.91 \\
\hline & Winter(Dec-March) & 600 & 37.24 \\
\hline \multirow[t]{4}{*}{ Time of Accident } & Morning & 629 & 28.72 \\
\hline & Afternoon & 295 & 13.42 \\
\hline & Evening & 510 & 23.28 \\
\hline & Night & 756 & 34.47 \\
\hline \multirow[t]{9}{*}{ Road Condition } & Broken road & 335 & 15.30 \\
\hline & Crowded road & 165 & 7.53 \\
\hline & Defected road & 431 & 19.68 \\
\hline & No problem & 1 & 0.046 \\
\hline & Narrow road & 83 & 3.79 \\
\hline & Other & 1 & 0.046 \\
\hline & Poor lighting & 406 & 18.54 \\
\hline & Road crossing & 388 & 17.72 \\
\hline & Speed breaker & 380 & 17.35 \\
\hline \multirow[t]{9}{*}{ Type of vehicle } & 3 Wheeler & 584 & 26.67 \\
\hline & Car & 6 & 0.27 \\
\hline & Cycle & 8 & 0.36 \\
\hline & HMV & 438 & 20.0 \\
\hline & Motor cycle & 744 & 33.97 \\
\hline & Other & 7 & 0.32 \\
\hline & Pedestrian injury & 241 & 11.00 \\
\hline & Pickup truck & 121 & 5.66 \\
\hline & Stationary & 41 & 1.87 \\
\hline \multirow[t]{5}{*}{ Vehicle } & Excessive speed & 909 & 41.50 \\
\hline & Faulty machine & 107 & 4.88 \\
\hline & Not applicable & 261 & 11.92 \\
\hline & No problem & 27 & 1.23 \\
\hline & Overload & 886 & 40.46 \\
\hline \multirow[t]{2}{*}{ Alcohol } & Yes & 296 & 13.26 \\
\hline & No & 1894 & 86.48 \\
\hline
\end{tabular}




\section{ORIGINAL ARTICLE}

\section{AUTHORS:}

1. Sanjeev Kumar Singh

2. Saurabh Agrawal

3. Rashmi Yadav

4. Shubhanshu Gupta

\section{PARTICULARS OF CONTRIBUTORS:}

1. Final Year Post Graduate, Department of Orthopaedics, Jhansi.

2. Assistant Professor, Department of Orthopaedics, Jhansi.

3. $2^{\text {nd }}$ Year Post Graduate, Department of Community Medicine, Jhansi.

\section{FINANCIAL OR OTHER}

COMPETING INTERESTS: None
4. $1^{\text {st }}$ Year Post Graduate, Department of Community Medicine, Jhansi.

\section{NAME ADDRESS EMAIL ID OF THE} CORRESPONDING AUTHOR:

Sanjeev Kumar Singh,

Room No. 80, P. G. Married Hostel,

M. L. B. Medical College,

Jhansi-284128,

Uttar Pradesh.

E-mail: sanjeev23021985@gmail.com

Date of Submission: 02/05/2015.

Date of Peer Review: 03/05/2015.

Date of Acceptance: 20/05/2015.

Date of Publishing: 27/05/2015. 